\title{
Covid lays bare the brittleness of a concentrated and consolidated food system
}

\author{
Mary K. Hendrickson ${ }^{1}$
}

Accepted: 25 April 2020 / Published online: 12 May 2020

(c) Springer Nature B.V. 2020

It has only taken 6 weeks for the Covid-19 pandemic to brutally expose the flaws of our modern food system-flaws documented by scholars for decades. ${ }^{1}$ Produce destroyed in fields because restaurants and food services are closed. Covid-19 hotspots emerging in meatpacking communities forcing closure of up to $20 \%$ of pork packing in the U.S. ${ }^{2}$ Farmers in alternative agrifood markets pivoting to online ordering and reorienting their supply away from restaurants and to retail or delivery. Low paid grocery store clerks and meat packing workers deemed essential but provided little protective gear or means of social distancing. ${ }^{3}$ Farmers facing euthanizing animals for lack of slaughter space. ${ }^{4}$ Food service workers losing jobs overnight fed through pop-up charity dinners. Farmworkers unable to cross closed borders in Europe or North America. Economic disaster forming long lines at emergency food distributions and potentially doubling the number of very hungry people globally to 265 million. $^{5}$

What is unique about Covid-19 is the food system is cracking in multiple sectors and multiple locations at once. Worker treatment, farmer viability, animal welfare and ecological sustainability were all pressing concerns prior to this moment. The pandemic glaringly illuminates that just-intime food supply chains lack the resilience to effectively respond to such a severe, multi-dimensional shock. This system has shown little capacity to fend off disruption, difficulty in stretching to accommodate change, and little redundancy or overlapping systems that provide fail-safe mechanisms.

This article is part of the TopicalCollection: Agriculture, Food \& Covid-19.

\footnotetext{
Mary K. Hendrickson

HendricksonM@missouri.edu

1 Division of Applied Social Sciences, University of Missouri, Columbia, USA
}

It has highlighted the lack of diversity in scale, form and organization across the system. Our only hope is that the precarity of the system, its potential losing of its core identity as a for-profit food system based on efficiency, specialization, standardization and centralization, will allow transition to a decentralized, diverse, and interconnected food system that can feed all of us now and in the future (Hendrickson 2015).

To build a resilient food system, we have to shine a light on the concentrated power of a handful of global firmshousehold names like Tyson, Bayer or Nestle, and less visible power players like the grain-trader Cargill (operating in 70 countries) or ChemChina (a giant in seeds and agrochemicals) or JBS (the largest meatpacker in the world) (ETC Group 2019). In a for-profit system, the boards and management of these companies have more power to decide what, where and how food is produced, who is doing the work, and even who gets to eat it than do farmers, workers, eaters or communities. In this for-profit system, food is simultaneously made cheap through the exploitation of nature, farmers and workers while being too expensive for poor households around the world. Covid-19 exposes the faults of concentrated power in food systems in coping with other slowermoving ecological disasters like soil degradation, decline in water quality and quantity and weather calamities due to climate change (Hendrickson et al. 2019).

The way forward is to reprioritize the main goal of any food system - to provide healthy, nutritious food for all people, now and in the future, in the face of a changing

\footnotetext{
1 Two issues of the Journal of Environmental Studies and Science were devoted to food system resilience and can be accessed here: https://foodresilience.org/.

${ }^{2}$ See https://www.dtnpf.com/agriculture/web/ag/news/artic le/2020/04/20/plants-suspend-operations-growing

${ }^{3}$ See https://www.supermarketnews.com/issues-trends/ufcw-cdcmandatory-covid-19-guidance-needed-grocery-workers.

${ }^{4}$ See https://www.beefmagazine.com/beef/covid-19-cuts-meat-proce ssing-capacity.

5 See https://www.wfp.org/news/covid-19-will-double-number-peopl e-facing-food-crises-unless-swift-action-taken.
} 
climate and declining natural resources. To do that we must pursue worker rights, animal welfare, farmer viability and ecological sustainability simultaneously because they are all tied together. We gain flexibility and adaptability in a decentralized system of production and consumption, with power distributed from the bottom up. We need a diversity of public, private and cooperative food and farm businesses, both small and large, that are transparently interconnected through multiple networks, to build redundancy and provide fallbacks when some organizations or networks fail.

No one approach at any given scale will prove effective. Instead we have to create a resilient food system through a combination of actions, strategies and policies at multiple levels that are ecological, democratic, and equitable within and across populations, generations and species.

\section{References}

ETC Group. 2019. Plate Tech Tonics: Mapping Corporate Power in Big Food. Accessed at: https://etcgroup.org/sites/www.etcgroup.org/ files/files/etc_platetechtonics_a4_nov2019_web.pdf.
Hendrickson, Mary K. 2015. Resilience in a concentrated and consolidated food system. Journal of Environmental Studies and Science 5: 418-431. https://doi.org/10.1007/s13412-015-0292-2.

Hendrickson, Mary K., Phillip H. Howard, and Douglas H. Constance. 2019. Power, Food and Agriculture: Implications for Farmers, Consumers and Communities. In Defense of Farmers: The Future of Agriculture in the Shadow of Corporate Power, ed. J.W. Gibson and S.E. Alexander, 13-61. Lincoln, NE: University of Nebraska Press.

Publisher's Note Springer Nature remains neutral with regard to jurisdictional claims in published maps and institutional affiliations.

Mary K. Hendrickson is an Associate Professor of Rural Sociology at the University of Missouri, where she serves as Co-Director of the Interdisciplinary Center for Food Security. She teaches sustainable food and farming courses at MU, and was a Fulbright Scholar to Iceland, teaching sustainable agriculture at the Agricultural University of Iceland. She is particularly interested in how farmers, consumers and communities are seeking to transform the structure of food and agriculture by building equitable, fair and resilient food systems. 